\title{
Successful remission of type B insulin resistance syndrome without rituximab in an elderly male
}

\author{
Marcio José Concepción-Zavaleta1, Sofía Pilar Ildefonso-Najarro1, \\ Esteban Alberto Plasencia-Dueñas ${ }^{1}$, María Alejandra Quispe-Flores' ${ }^{1}$ \\ Cristian David Armas-Flórez² and Laura Esther Luna-Victorio ${ }^{1}$
}

'Division of Endocrinology, Hospital Nacional Guillermo Almenara Irigoyen, Lima, Peru and 2School of Medicine, Universidad Nacional de Trujillo, Trujillo, Peru
Correspondence should be addressed to C D Armas-Flórez

Email

davidarmasflorez@gmail.com

\section{Summary}

Type B insulin resistance syndrome (TBIR) is a rare autoimmune disease caused by antibodies against the insulin receptor. It should be considered in patients with dysglycaemia and severe insulin resistance when other more common causes have been ruled out. We report a case of a 72-year-old male with a 4-year history of type 2 diabetes who presented with hypercatabolism, vitiligo, acanthosis nigricans, and hyperglycaemia resistant to massive doses of insulin (up to $1000 \mathrm{U} /$ day). Detection of anti-insulin receptor antibodies confirmed TBIR. The patient received six pulses of methylprednisolone and daily treatment with cyclophosphamide for 6 months. Response to treatment was evident after the fourth pulse of methylprednisolone, as indicated by weight gain, decreased glycosylated haemoglobin and decreased requirement of exogenous insulin that was later discontinued due to episodes of hypoglycaemia. Remission was eventually achieved and the patient is currently asymptomatic, does not require insulin therapy, has normal glycaemia and is awaiting initiation of maintenance therapy with azathioprine. Thus, TBIR remitted without the use of rituximab. This case highlights the importance of diagnosis and treatment in a timely fashion, as well as the significance of clinical features, available laboratory findings and medication. Large controlled studies are required to standardise a therapeutic protocol, particularly in resource-constrained settings where access to rituximab is limited.

\section{Learning points:}

- Type B insulin resistance syndrome is a rare autoimmune disorder that should be considered in patients with dysglycaemia, severe insulin resistance and a concomitant autoimmune disease.

- Serological confirmation of antibodies against the insulin receptor is not necessary in all cases due to the high associated mortality without timely treatment.

- Although there is no standardised immunosuppressive treatment, a protocol containing rituximab, cyclophosphamide and steroids has shown a significant reduction in previously reported mortality rates.

- The present case, reports successful remission in an atypical patient using cyclophosphamide and methylprednisolone, which is an effective therapy in countries in which rituximab is not covered by health insurance.

- When there is improvement in the hypercatabolic phase, the insulin dose should be reduced and/or discontinued to prevent hypoglycaemia; a mild postprandial hyperglycaemic state should be acceptable. 


\section{Background}

Insulin resistance is a pathophysiological event of great relevance and prevalence in public health, and is predominantly associated with type 2 diabetes mellitus. In some cases, patients present with severe insulin resistance, resulting in refractory hyperglycaemia despite treatment with multiple oral hypoglycaemic agents and/ or high doses of insulin (1).

Severe insulin resistance is also associated with drugs such as corticosteroids, atypical antipsychotics, calcineurin inhibitors, protease inhibitors and oral contraceptives, as well as endocrine disorders, such as acromegaly, thyrotoxicosis, Cushing's syndrome, and pheochromocytoma $(1,2,3)$. However, if these conditions are ruled out, it is necessary to consider severe insulin resistance syndromes, of which there are three types: type $\mathrm{A}$, which is caused by a mutation in the insulin receptor gene; type $\mathrm{B}$, which is caused by antibodies against the insulin receptor; and type $\mathrm{C}$, which is of unknown pathogenesis, but is believed to be due to decreased tyrosine kinase activity (1).

Type B insulin resistance syndrome (TBIR) is a rare disorder that is predominantly seen in African-Americans (4). It is typically reported in women aged 15-69 years, and is associated with autoimmune conditions, such as systemic lupus erythematosus, rheumatoid arthritis, and Hashimoto's thyroiditis, or found as a paraneoplastic manifestation of conditions such as Hodgkin's disease and multiple myeloma $(3,5)$.

Prevalence of TBIR is unknown, since the epidemiological data is mainly based on case series studies. A recent systematic review reported only 119 clinical cases worldwide throughout history (5). Cases are uncommon in Latin America, and only two have been previously reported in Peru (6). The mortality rate is around $50 \%$ without treatment, and is mainly attributed to hypoglycaemia $(3,7)$.

The goals of treatment are to reverse the hypercatabolic state using high doses of insulin, eliminate autoantibodies using immunosuppressive drug therapy, and prevent hyperglycaemic complications, including vascular issues and ketosis $(1,3)$.

We present a case of TBIR in a patient with atypical epidemiological characteristics, including male gender and advanced age associated with vitiligo and persistent eosinophilia. He received an immunosuppressive drug regimen that did not include rituximab and achieved successful remission of the disease.

\section{Case presentation}

The case was a 72-year-old male from Huánuco, Peru. Four years prior to admission, the patient experienced episodes of polydipsia, polyuria and polyphagia, and was diagnosed with diabetes mellitus by an endocrinologist. Initial treatment using metformin (850 $\mathrm{mg}$ TID), glibenclamide (5 mg BID) and dietary changes was unsuccessful, and the patient remained symptomatic with subsequent unintentional weight loss.

\section{Investigation}

Five months prior to admission, oral antidiabetic medication was suspended and treatment with Neutral

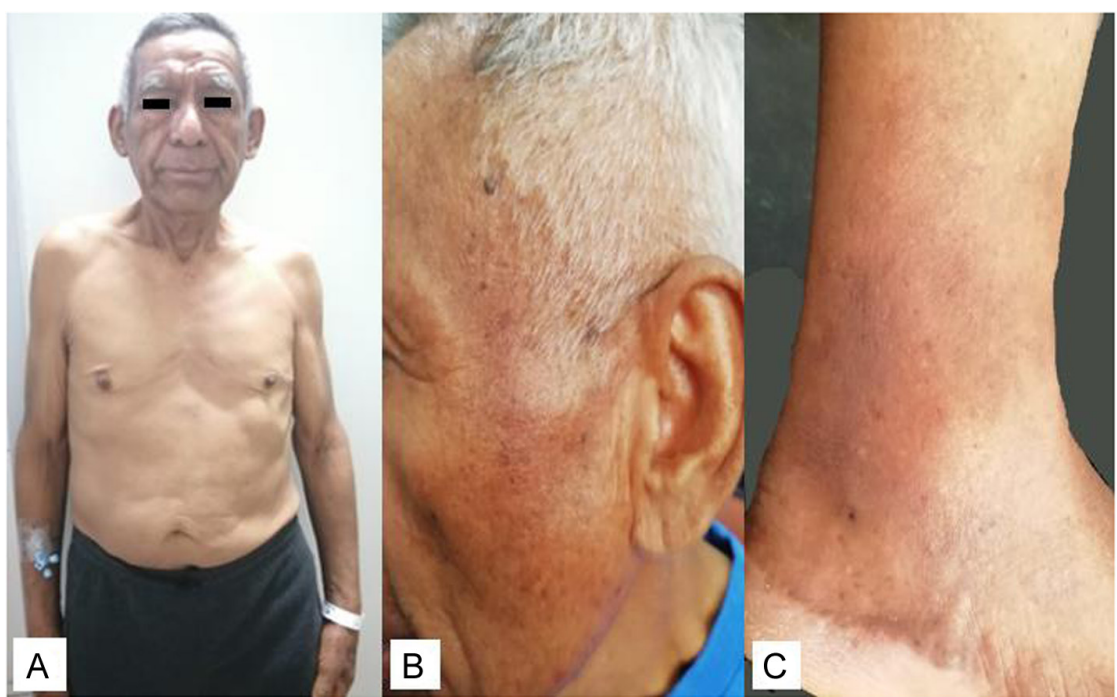

\section{Figure 1}

Clinical manifestations of the patient. (A) Abdominal lipodystrophy and muscle wasting, showing a hypercatabolic state; achromic macules with irregular edges in (B) face and (C) lower limbs, compatible with vitiligo. 
Protamine Hagedorn (NPH) insulin was initiated at doses of $30 \mathrm{U}$ in the morning and $20 \mathrm{U}$ at night, as well as 7 $\mathrm{U}$ of regular insulin before breakfast, lunch and dinner. The patient persisted with poorly controlled glycaemia; therefore, insulin doses were progressively increased to $72 \mathrm{U}$ of NPH in the morning and night, and $25 \mathrm{U}$ of regular insulin before breakfast, $30 \mathrm{U}$ before lunch, and

Table 1 Laboratory findings during hospitalisation, before immunosuppressive treatment.

\begin{tabular}{|c|c|c|}
\hline Laboratory parameters & Normal range & Results \\
\hline $\begin{array}{l}\text { Complete blood count } \\
\text { haemoglobin }(g / d L)\end{array}$ & $13.5-17.5$ & 10.2 \\
\hline $\begin{array}{l}\text { White blood } \\
\text { cells }\left(/ \mathrm{mm}^{3}\right)\end{array}$ & $4500-11000$ & 4180 \\
\hline Eosinophils (\%) & $1-3$ & 13.50 \\
\hline $\begin{array}{l}\text { Segmented } \\
\text { neutrophils (\%) }\end{array}$ & $54-62$ & 60 \\
\hline Lymphocytes (\%) & $25-33$ & 19.8 \\
\hline Platelets (/mm³) & $150000-400000$ & 161000 \\
\hline \multicolumn{3}{|l|}{ Blood biochemistry } \\
\hline Urea $(\mathrm{mg} / \mathrm{dL})$ & $10-40$ & 66 \\
\hline Creatinine (mg/dL) & $0.6-1.2$ & 0,76 \\
\hline AST (U/L) & $<35$ & 58 \\
\hline $\operatorname{ALT}(\mathrm{U} / \mathrm{L})$ & $<35$ & 83 \\
\hline $\operatorname{ALP}(\mathrm{U} / \mathrm{L})$ & $20-130$ & 174 \\
\hline GGTP (U/L) & $9-64$ & 110 \\
\hline Albumin (g/L) & $35-55$ & 32 \\
\hline Globulin (g/L) & $23-35$ & 21 \\
\hline Sodium (mmol/L) & $136-145$ & 134 \\
\hline Potassium (mmol/L) & $3.5-5.0$ & 4.2 \\
\hline $\begin{array}{l}\text { Postprandial } \\
\text { C-peptide (ng/mL) }\end{array}$ & 3-9 & 5.5 \\
\hline $\mathrm{HDL}(\mathrm{mg} / \mathrm{dL})$ & $>50$ & 38 \\
\hline $\mathrm{LDL}(\mathrm{mg} / \mathrm{dL})$ & $<130$ & 67 \\
\hline Triglycerides (mg/dL) & $<150$ & 47 \\
\hline \multicolumn{3}{|l|}{ Tumor markers } \\
\hline CA 19-9 (U/mL) & $<40$ & 13.39 \\
\hline $\begin{array}{l}\text { Alpha fetoprotein } \\
(\mathrm{ng} / \mathrm{mL})\end{array}$ & $<10$ & 2.7 \\
\hline $\mathrm{CEA}(\mathrm{ng} / \mathrm{mL})$ & $<2.5$ & 2.89 \\
\hline $\begin{array}{l}\beta_{2} \text {-microglobulin } \\
(\mathrm{ng} / \mathrm{mL})\end{array}$ & $<2500$ & 2112 \\
\hline \multicolumn{3}{|l|}{ Autoantibodiy tests } \\
\hline ANA, ANCA & & Negatives \\
\hline $\begin{array}{l}\text { Anti-insulin receptor } \\
\text { antibodies }(\mathrm{U} / \mathrm{mL})\end{array}$ & $<1$ & Positive (4.12) \\
\hline $\begin{array}{l}\text { Insulin } \\
\text { autoantibodies (U/L) }\end{array}$ & $<12$ & Indeterminate (12.8) \\
\hline $\begin{array}{l}\text { Anti-thyroglobulin } \\
\text { antibodies }(\mathrm{U} / \mathrm{mL})\end{array}$ & $<35$ & Negative (17.1) \\
\hline $\begin{array}{l}\text { Anti-microsomal } \\
\text { antibodies }(\mathrm{U} / \mathrm{mL})\end{array}$ & $<60$ & Negative $(<15)$ \\
\hline
\end{tabular}

ALP, alkaline phosphatase; ALT, alanine aminotransferase; ANA antinuclear antibodies; ANCA, antineutrophil cytoplasmic antibodies; AST, aspartate aminotransferase; CEA, carcinoembryogenic antigen; GGTP, $\gamma$-glutamyltranspeptidase.
$25 \mathrm{U}$ before dinner, and metformin (850 $\mathrm{mg}$ TID) was resumed. The patient presented at our hospital emergency room with persistent symptoms and a random glycaemia measurement of $357 \mathrm{mg} / \mathrm{dL}$ and was hospitalised. At admission, physical examination revealed a cachectic patient with height, body weight, and BMI of $160 \mathrm{~cm}, 48$ $\mathrm{kg}$, and $18 \mathrm{~kg} / \mathrm{m}^{2}$, respectively. We found vitiligo in his face, back, and lower limbs (Fig. 1), acanthosis nigricans in his neck and armpits and distal sensory-motor polyneuropathy in lower limbs. He had no family history of autoimmune disease.

Regular insulin was initiated via the subcutaneous route. Insulin doses were progressively increased, and he required $>1 \mathrm{U} / \mathrm{kg} /$ day, but did not achieve glycaemic targets. Additionally, the patient received pioglitazone 30 $\mathrm{mg}$ /day, which was discontinued 2 weeks later, because it was not part of the therapeutic protocol for our first suspected diagnosis.

We concluded that the patient had severe insulin resistance due to the requirement of $>2 \mathrm{U} / \mathrm{kg} / \mathrm{day}$ of insulin. Therefore, neoplastic, autoimmune, pharmacological and infectious causes were ruled out. A thoraco-abdomino-pelvic tomography with contrast, TORCH (toxoplasmosis, rubella, cytomegalovirus and herpes simplex virus) profile, ELISA test for human immunodeficiency virus, serology for human $\mathrm{T}$ cell leukaemia virus type 1, immunoglobulin dosing, tumour markers, electrophoretic proteinogram, antinuclear antibodies, antineutrophil cytoplasmic antibodies, antibodies directed against extractable nuclear antigens and pancultures all showed normal results. Blood biochemistry showed slight liver dysfunction, low high-density lipoproteins cholesterol (38 mg/dL), low triglycerides (47 mg/dL), and high HbAlc (17.9\%). The blood count showed persistent eosinophilia, ranging from 13 to $20 \%$. Finally, RIA for insulin autoantibodies has shown a borderline positive value (Table 1).

\section{Treatment}

As the tests were negative, TBIR was considered as a diagnostic hypothesis, and RIA (Synlab, Barcelona, Spain) revealed the presence of antibodies against the insulin receptor with a value of 4.12 (where $<1$ is negative). Consequently, the patient received five sessions of plasmapheresis, but showed no significant change in the glycaemic values.

The case was discussed in a multidisciplinary team meeting. Immunosuppressive therapy was initiated using methylprednisolone at $1 \mathrm{~g}$ IV for 2 days, repeated 2 weeks 
later and then every 4 weeks. The patient was also started on cyclophosphamide (50 mg BID) until remission was achieved. Rituximab was not included in the treatment protocol, as it is not approved for TBIR in Peru.

\section{Outcome and follow-up}

The total insulin dose prior to the start of the immunosuppressive therapy was $1000 \mathrm{U} /$ day, and was decreased progressively after the fourth pulse of methylprednisolone. In total, the patient received six pulses of methylprednisolone and cyclophosphamide for six months. After this, immunosuppressive and insulin therapies were suspended due to recurrent hypoglycaemia, thus indicating the remission phase as shown by improved hyperglycaemia and the discontinuation of insulin therapy $(8,9)$. Concomitantly, HbAlc values decreased, followed by progressive weight gain (Table 2).

Three weeks after the end of immunosuppressive therapy, he remains asymptomatic, does not require insulin and has normal blood glucose levels. Initiation of maintenance therapy with azathioprine (100 mg/day) is pending.

\section{Discussion}

Insulin resistance is a subnormal biological response to insulin, which, in combination with relative insulin deficiency, defines type 2 diabetes mellitus (10). In rare cases, patients develop severe insulin resistance that requires $>2 \mathrm{U} / \mathrm{kg}$ or $>200 \mathrm{U}$ total daily exogenous insulin $(1,3)$. The doses of insulin used in the treatment of reported TBIR patients range from 54 to $57600 \mathrm{U} /$ day, with a median of $1747 \mathrm{U} /$ day (5). In the present case, the requirement for insulin was up to $1000 \mathrm{U} /$ day, which is equivalent to $18 \mathrm{U} / \mathrm{kg} /$ day.

Diagnosis of TBIR is based on the presence of the antibodies against the insulin receptor, detected by immunoprecipitation, which is the gold standard for diagnosis, preferably during the hyperglycaemic phase (5). It is difficult to confirm the diagnosis by this test because it is only performed in select research laboratories worldwide. In the present case, RIA was used, however, this type of assay is selective for antibodies that inhibit insulin binding, and not all antireceptor antibodies have this property (11). Likewise, it is postulated that the reason why RIA for insulin autoantibodies was borderline positive $(12.8 \mathrm{U} / \mathrm{L})$, would be due to cross-reactivity with the test for antibodies against the insulin receptor.

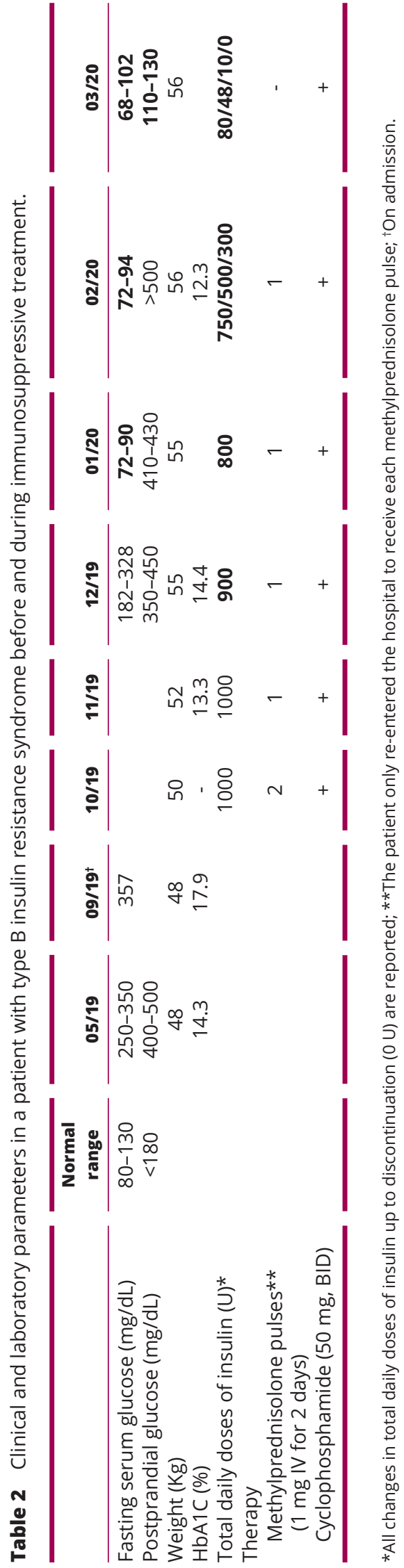


High antibody titers have been demonstrated to act as receptor antagonists, while low titers act as stimulatory agonists, resulting in a clinical spectrum that ranges from severe hyperglycaemia, which is the most frequent clinical feature, to intractable hypoglycaemia $(2,3)$. In our patient, clinically, the titre of antibodies was presumed to be high given the severity of insulin resistance. In this way, when a patient is critically ill and requires urgent treatment, providers may need to rely on clinical features and available laboratory findings to diagnose TBIR (2).

This is the third case of TBIR to be reported in Peru. The other two cases were middle-aged women, one without active disease, but showing positive markers for Hashimoto's thyroiditis and mixed connective tissue disease, whereas the other woman had rheumatoid arthritis, systemic lupus erythematosus, and Hashimoto's thyroiditis (6). It should be noted that most patients do not me et al. the criteria for a specific autoimmune disease, but may have one or more autoimmune features, such as alopecia, nephritis, anaemia, leukopenia, and positive antinuclear antibodies (12). Our patient had vitiligo and eosinophilia, suggesting an association with another autoimmune disorder.

TBIR commonly presents with severe diabetes mellitus refractory to very high doses of insulin, significant weight loss, severe androgenism, and acanthosis nigricans (3), although none of these features are pathognomonic of the diagnosis. However, it is suggested that the biochemical triad of markedly elevated fasting insulin concentrations, hyperadiponectinemia, and low fasting triglyceride concentrations in an individual with acanthosis nigricans and history of an autoimmune disease can be considered as a clinical definition (3). In the present case, the patient presented with acanthosis nigricans and low triglycerides (47 mg/dL).

In terms of immunosuppressive treatment, there have been no reports of large placebo-controlled trials, and the literature is limited to case reports and small patient populations (9) with significant variability; therefore, there is not a standardised treatment scheme for this syndrome. We used the protocol established by Klubo-Gwiezdzinska et al. (8), using immunosuppressive therapy based on cycles of methylprednisolone $1 \mathrm{~g}$ IV for 2 days and cyclophosphamide $50 \mathrm{mg}$ (one tablet) BID. Rituximab, a monoclonal anti-CD20 antibody, was included in this protocol, since it previously showed high efficacy and safety in inducing initial remission (1, $7,13)$; however, it was not administered in the present case since it is not covered for this disease by Peruvian health insurance and patients cannot obtain it due to its high cost, restricting its use significantly. This protocol led to a significant reduction in previously reported mortality rates (14).

There are reports of remission of TBIR without the use of rituximab. In one case, betamethasone was administered at low doses for 30 months (15). Two other cases were reported in Peru: in the first case, $100 \mathrm{mg}$ of cyclophosphamide was given orally for 3 weeks; and in the second case, eight pulses of $1 \mathrm{~g}$ of cyclophosphamide every 28 days in combination with prednisone $20 \mathrm{mg}$ /day were administrated, with remission occurring 1 year later (6). In the present case, the patient received six pulses of methylprednisolone and 6 months of cyclophosphamide treatment, and achieved remission, defined as euglycaemia without the use of insulin and normalisation of fasting insulin concentrations (Table 2). This period holds the highest risk of hypoglycaemia and fatalities (3).

The time to reach remission varies and is typically between 6 and 27 months. Spontaneous remission is reached in 33\% of patients, 33\% will remit in response to therapy, and the rest will not achieve remission (8, 16). In the present case, the time to reach remission was 6 months. It is unknown whether maintenance immunosuppressive therapy using azathioprine is required to prevent recurrence or how long it should be maintained. The patient is currently waiting to receive maintenance immunosuppressive therapy with azathioprine, as established by the protocol created by Klubo-Gwiezdzinska et al. $(3,8)$.

In conclusion, TBIR in an older male is a rare autoimmune disease, requiring a timely diagnosis and treatment due to the high association with mortality. In our experience, the combined regimen of cyclophosphamide and corticosteroid pulses was effective in achieving remission without the use of rituximab. Large randomised clinical trials and long-term follow-up data are required to define the best therapeutic protocol for this group of patients, especially in countries where the use of rituximab is limited.

\section{Declaration of interest}

The authors declare that there is no conflict of interest that could be perceived as prejudicing the impartiality of the research reported.

\section{Funding}

This research did not receive any specific grant from any funding agency in the public, commercial or not-for-profit sector. 


\section{Patient consent}

Written informed consent for publication of their clinical details and clinical images was obtained from the patient.

\section{Author contribution statement}

Marcio Jose Concepción-Zavaleta was part of the treating team and was the main writer and case reviewer and performed literature overview. Sofia Pilar Ildefonso-Najarro was part of the treating team and a case reviewer. Esteban Alberto Plasencia-Dueñas and María Alejandra QuispeFlores were part of the treating team and performed written contribution to body of text. Cristian David Armas-Flórez was a case reviewer, translator and editor and prepared the manuscript. Laura Esther Luna-Victorio was part of the treating team and a case reviewer.

\section{References}

1 Hong JH, Kim HJ, Park KS \& Ku BJ. Paradigm shift in the management of type B insulin resistance. Annals of Translational Medicine 20186 S98. (https://doi.org/10.21037/atm.2018.11.21)

2 Kim HN, Fesseha B, Anzaldi L, Tsao A, Galiatsatos P \& Sidhaye A. Antibody-mediated extreme insulin resistance: a report of three cases. American Journal of Medicine 2018131 102-106. (https://doi. org/10.1016/j.amjmed.2017.08.004)

3 Willard DL, Stevenson M \& Steen Kamp D. Type B insulin resistance syndrome. Current Opinion in Endocrinology, Diabetes, and Obesity 2016 23 318-323. (https://doi.org/10.1097/MED.0000000000000263)

4 Viswanathan L \& Sirisena I. Immunosuppressive therapy in treatment of refractory hypoglycemia in Type B insulin resistance: a case report. Journal of the Endocrine Society 20171 1435-1439. (https://doi.org/10.1210/js.2017-00292)

5 Martins LM, Fernandes VO, Carvalho MMD, Gadelha DD, Queiroz PC \& Montenegro Junior RM. Type B insulin resistance síndrome: a systematic review. Archives of Endocrinology and Metabolism 202064 337-348. (https://doi.org/10.20945/23593997000000257)

6 Zelada H, Gamarra D, Arbañil H \& Manrique H. Type B insulin resistance in Peru. American Journal of the Medical Sciences 2017353 258-262. (https://doi.org/10.1016/j.amjms.2016.07.001)
7 Manikas ED, Isaac I, Semple RK, Malek R, Führer D \& Moeller LC. Successful treatment of type B insulin resistance with rituximab. Journal of Clinical Endocrinology and Metabolism 2015100 1719-1722. (https://doi.org/10.1210/jc.2014-3552)

8 Klubo-Gwiezdzinska J, Lange M, Cochran E, Semple RK, Gewert C, Brown RJ \& Gorden P. Combined immunosuppressive therapy induces remission in patients with severe Type B insulin resistance: a prospective cohort study. Diabetes Care 201841 2353-2360. (https:// doi.org/10.2337/dc18-0884)

9 Malek R, Chong AY, Lupsa BC, Lungu AO, Cochran EK, Soos MA, Semple RK, Balow JE \& Gorden P. Treatment of type B insulin resistance: a novel approach to reduce insulin receptor autoantibodies. Journal of Clinical Endocrinology and Metabolism 2010 95 3641-3647. (https://doi.org/10.1210/jc.2010-0167)

10 Lin Y \& Sun Z. Current views on type 2 diabetes. Journal of Endocrinology 2010204 1-11. (https://doi.org/10.1677/JOE-090260)

11 Jacobs S \& Cuatrecasas P. Insulin receptor antibodies. In Methods in Enzymology, Vol. 74, pp. 471-478. Eds J Langone \& H Van Vunakis. Elsevier, 1981. (https://doi.org/10.1016/0076-6879(81)74033-3)

12 Moller D, Vidal-Puig A \& Azziz R. Severe insulin-resistance hyperandrogenic syndromes. In Contemporary Endocrinology: Androgen Excess Disorders in Women, 2nd ed., pp. 129-138. Eds R Azziz, J Nestler \& D Dewailly. New Jersey: Humana Press, 2006. (https://doi. org/10.1007/978-1-59745-179-6_11)

13 Iseri K, Iyoda M, Shikida Y, Inokuchi T, Morikawa T, Hara N, Hirano T \& Shibata T. Rituximab for the treatment of type B insulin resistance syndrome: a case report and review of the literature. Diabetic Medicine 201734 1788-1791. (https://doi.org/10.1111/ dme.13524)

14 Willard D, Upadhyay J, Kim C \& Steenkamp D. Diabetic ketoacidosis without diabetes. Journal of Clinical Endocrinology and Metabolism 2016101 3870-3873. (https://doi.org/10.1210/jc.2016-2146)

15 Kotani M, Tamura N, Inoue T \& Tanaka I. A case of type B insulin resistance syndrome treated with low-dose glucocorticoids. Endocrinology, Diabetes and Metabolism Case Reports 20192019 19-0115. (https://doi.org/10.1530/EDM-19-0115)

16 Arioglu E, Andewelt A, Diabo C, Bell M, Taylor SI \& Gorden P. Clinical course of the syndrome of autoantibodies to the insulin receptor (type B insulin resistance): a 28-year perspective. Medicine 200281 87-100. (https://doi.org/10.1097/00005792-200203000$00001)$

Received in final form 13 September 2020 Accepted 18 September 2020 